\title{
Role of initial effective stress on the thermal volume change of normally consolidated clay
}

\author{
Radhavi Samarakoon ${ }^{1}$, and John S. McCartney ${ }^{1, *}$ \\ ${ }^{1}$ University of California San Diego, Department of Structural Engineering, 9500 Gilman Drive, La Jolla, CA 92093-0085, USA
}

\begin{abstract}
This paper focuses on the results from thermal triaxial tests on normally consolidated Georgia Kaolinite. The hypothesis evaluated in this study is whether the initial mean effective stress has an impact on the thermal volume change encountered during drained heating. To that effect, specimens at three different initial mean effective stresses were considered in this study. The clay specimens were first isotropically consolidated to a normally consolidated state, then subjected to a drained heating cooling cycle followed by further mechanical loading to higher effective stresses. The results indicate contractive volumetric strain during drained heating where the volumetric strain was found to increase with increasing initial mean effective stress. A rebound in volume was observed during subsequent cooling where the net change in volume transitioned from zero volume change of the specimen to net contraction of the specimen after a heating cooling cycle as the initial mean effective stress increased. The results indicate the need for considering the effect of initial mean effective stress when assessing in-situ heating as a method of soil improvement.
\end{abstract}

\section{Introduction}

Improving soft soil deposits for construction is a crucial task for geotechnical engineers to avoid problems such as excessive settlements, bearing capacity failures and liquefaction. The use of in-situ heating as a method of soil improvement has been investigated by several researchers in recent studies $[1,2]$. This technique uses geothermal heat exchangers embedded in a soft clay deposit to conduct heat to the surrounding soil where they can also be combined with vertical drains during the preconsolidation stage to expedite the consolidation process. Furthermore, the heat exchangers can be used as an underground heat storage system for buildings after the soil improvement process. These subsurface geothermal heat exchangers can be arranged in vertical or horizontal configurations depending on the extent of soil improvement required. When assessing the feasibility of thermal soil improvement techniques, it is important to study the thermo-mechanical performance of soft clays at different initial mean effective stresses indicative of different depths in a soil deposit.

It has been observed by many researchers that drained heating of normally consolidated soils lead to plastic volumetric contraction and an increase in undrained shear strength [3-5]. Subsequent cooling of the soil is expected to lead to elastic contraction. Mechanical loading after a heating cooling cycle will result in an apparent overconsolidation state as a result of the thermal hardening effect experienced by the soil [6-8]. The soil regains a normally consolidated state with further loading where it yields at a higher mean effective stress than before.

Several constitutive models have been developed to predict the thermo-mechanical behaviour of soft clays [7-9]. Most of these models assume that the thermal volume change of normally consolidated clays during drained heating is independent of the initial mean effective stress. However, these models were defined based on tests carried out on initially overconsolidated specimens thermo-mechanically loaded to a normally consolidated state. Isothermal compression tests carried out at elevated temperatures resulted in compression curves with slopes similar to that of the compression curve at room temperature but with a shift to the left. The results obtained from these tests were used to predict the thermal hardening behaviour of normally consolidated clays. In the thermo-mechanical constitutive models mentioned above, heating normally consolidated clays will lead to a shift in the preconsolidation stress, an expansion of the yield surface, and contractile volume change, as shown schematically in Figure 1. An interesting observation from these constitutive models is that all normally consolidated clays are expected to have the same hardening response and same thermal volume change regardless of the initial void ratio.

On the other hand, subjecting normally consolidated clay specimens at different initial void ratios, indicative of different depths to drained heating at constant stress conditions may results in different thermal volume changes depending on their initial stress state. Limited experimental data available for initially normally

\footnotetext{
* Corresponding author: mccartney@ucsd.edu
} 
consolidated soils under different initial mean effective stresses indicate that thermal volume change is dependent on the initial mean effective stress $[5,10,17]$. A study on the thermal behaviour of Boom clay specimens was conducted by [17] where the specimens were first isotropically consolidated and then subjected to a drained heating cooling cycle at constant effective stress. Figure 2 shows the thermal volume change results obtained for normally consolidated Boom clay specimens at two different initial mean effective stress values of 1.2 and $3.85 \mathrm{MPa}$ respectively. A difference in the thermal volumetric strain for a given temperature can be observed based on the results. In this particular study a higher initial mean effective stress has resulted in a lower amount of volumetric strain whereas a higher volumetric strain was obtained at a lower initial mean effective stress. [10] conducted a similar study on illitic clay where the specimens were first isotropically consolidated and then subjected to drained heating. The thermal volume change of normally consolidated specimens was observed to be dependent on the initial mean effective stress. Furthermore, in a previous study by the authors [5], thermal volume change during drained heating of normally consolidated kaolinite specimens was observed to be dependent on the initial mean effective stress.

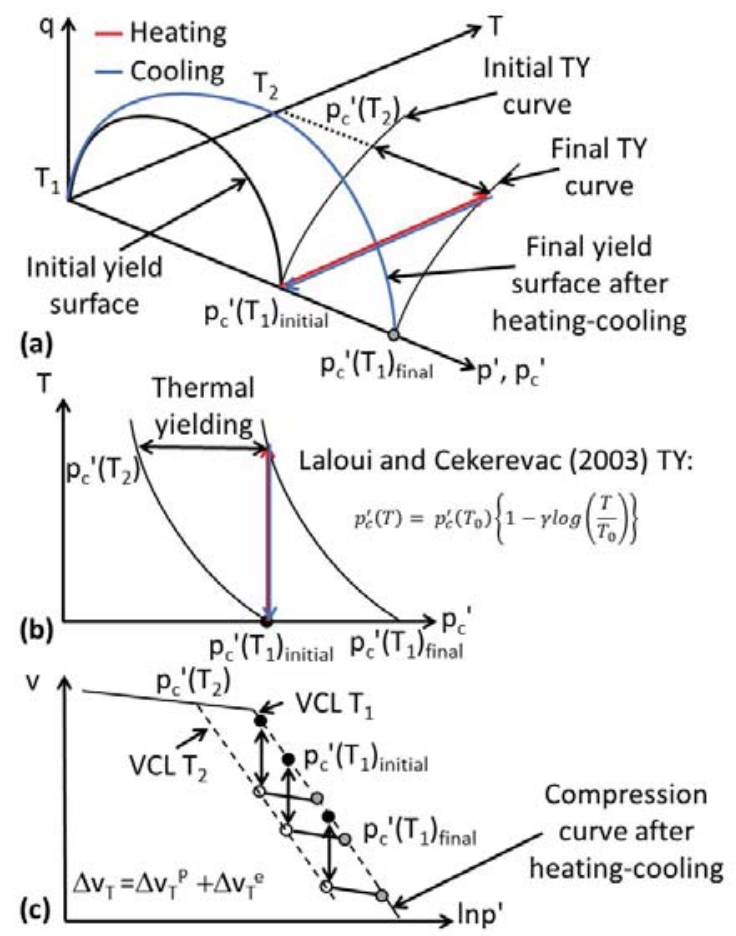

Fig. 1. Thermal hardening of normally consolidated soils during a heating-cooling cycle: (a) Yield surface in q-p'-T space; (b) Evolution in the thermal yield (TY) curve during heating of a normally consolidated clay; (c) Thermal volume change and effects on subsequent mechanical loading of normally consolidated clay.

These observations from previous studies in the literature call for further investigation on the role of initial mean effective stress on the thermal consolidation of normally consolidated clays. In this regard, this study presents the results obtained from thermal triaxial tests on saturated normally consolidated clay specimens at different initial mean effective stresses to interpret the possible impacts of the initial mean effective stress (and corresponding initial void ratio), and to provide guidance on the development of future constitutive models for the thermal response of normally consolidated clays.

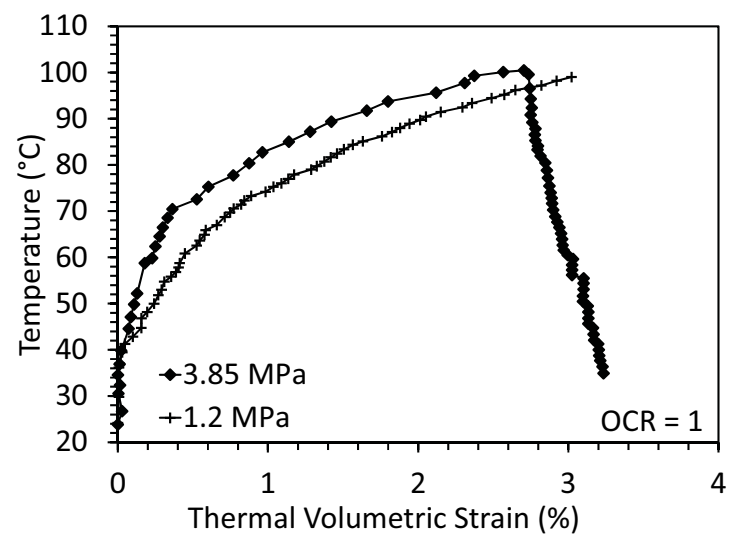

Fig. 2. Thermal volume change of Boom clay under different initial mean effective stresses [17].

\section{Material and test methods}

\subsection{Material}

Commercial Kaolinite clay obtained from M\&M Clays Inc. of McIntyre, GA was used in this study. Properties of the clay are given in Table 1. These properties include the compression indices obtained in an isotropic compression test at room temperature.

Table 1. Properties of the Kaolinite clay.

\begin{tabular}{|c|c|}
\hline Parameter & Value \\
\hline Liquid Limit & $47 \%$ \\
\hline Plasticity Index & 19 \\
\hline Specific Gravity & 2.6 \\
\hline Slope of VCL $(\lambda)$ & 0.09 \\
\hline Slope of RCL $(\kappa)$ & 0.02 \\
\hline USCS Classification & $\mathrm{CL}$ \\
\hline
\end{tabular}

\subsection{Experimental set-up}

A modified triaxial system developed by [11] was used to perform the laboratory tests in this study. A schematic of the system is shown in Figure 3. The system comprised of a Pyrex pressure vessel capable of withstanding higher temperatures and pressures applied during testing. The temperature within the cell was 
controlled by circulating heated water from a temperature-controlled circulating bath through a stainless-steel U-shaped pipe placed inside the cell. Uniform mixing of cell water was achieved by using a circulation pump able to accommodate high temperatures and pressures. The cell fluid temperature was measured using a thermocouple and a temperature recorder having an accuracy of $0.5^{\circ} \mathrm{C}$. The cell pressure was applied using a flow pump and the back-pressure was controlled using a pressure panel. A pore water pressure transducer was used to monitor the changes in pore water pressure during heating and cooling.

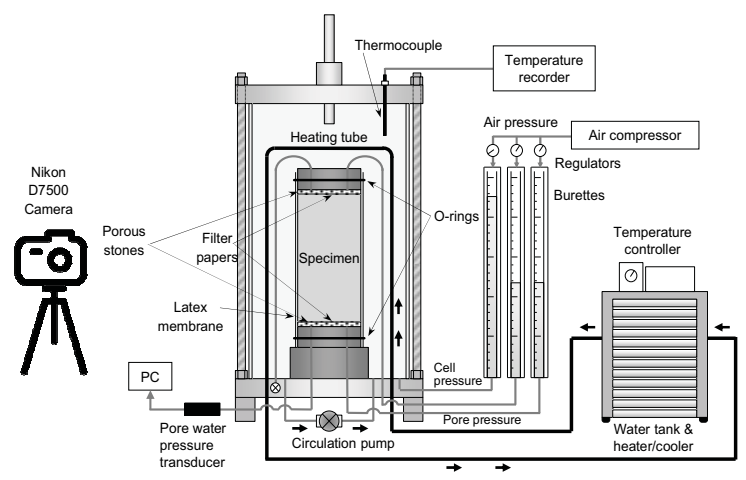

Fig. 3. Thermal triaxial set-up.

In addition to monitoring drainage from the specimen during heating and cooling, two high resolution cameras (Nikon D7500) were used to capture images of the specimen to measure changes in volume using an approach like that of [12]. The images were captured from two planes of the specimen which are perpendicular to each other at different time intervals throughout the test. The total specimen volume was assumed to consist of discrete volumes associated with a series of stacked disks where the height of a single disk was one vertical pixel and the diameter was the number of horizontal pixels. The average volume obtained by the two image planes was taken as the specimen volume at a given time.

\subsection{Procedure}

The clay specimens were prepared by mixing clay powder with deionized water in a mixer to form a slurry with a water content of $130 \%$. The slurry was then poured into a steel hollow cylinder of diameter $88.9 \mathrm{~mm}$. Porous stones and filter paper were placed at the top and bottom of the slurry. The slurry was first consolidated using a compression frame at a constant rate of $0.04 \mathrm{~mm} / \mathrm{min}$ for 48 hours. Then it was subjected to constant vertical stresses of $26,52,103$ and $181 \mathrm{kPa}$ in 24 hour-long increments. The sedimented clay layer was then extracted and trimmed to a smaller cylindrical specimen with a diameter of $72.4 \mathrm{~mm}$, suitable for testing in the thermal triaxial cell.

Once placed in the thermal triaxial cell, the specimen was back-pressure saturated by applying cell pressure and back-pressure in stages until the Skempton's pore water pressure parameter B value was at least 0.95 . The specimen was then isotropically consolidated to a desired mean effective stress. A total of three kaolinite specimens were tested in this study which were isotropically consolidated to mean effective stress values of 150,200 and $250 \mathrm{kPa}$ respectively. The specimens were at normally consolidated conditions at these stress states. After the consolidation stage, each specimen was subjected to a drained heating cooling cycle where the drainage valves at the top and the bottom of the specimen were kept open. During heating, the temperature was increased from $23{ }^{\circ} \mathrm{C}$ to $57{ }^{\circ} \mathrm{C}$ in 5 increments and each increment was maintained until the volume change stabilized. Then the specimens were cooled back to room temperature in a similar manner. Following a heating cooling cycle, the specimens were isotropically loaded in increments up to a desired mean effective stress.

\section{Experimental results and discussion}

As described in the experimental procedures, the saturated normally consolidated kaolinite specimens at different initial mean effective stresses were subjected to a drained heating cooling cycle. Typical volume change results during heating showed volumetric contraction whereas volumetric expansion was observed during cooling. The changes in void ratio during heating and cooling along with the corresponding temperature profile for the clay specimens with initial mean effective stresses of 150, 200, and $250 \mathrm{kPa}$ are shown in Figures 4, 5 , and 6 , respectively.

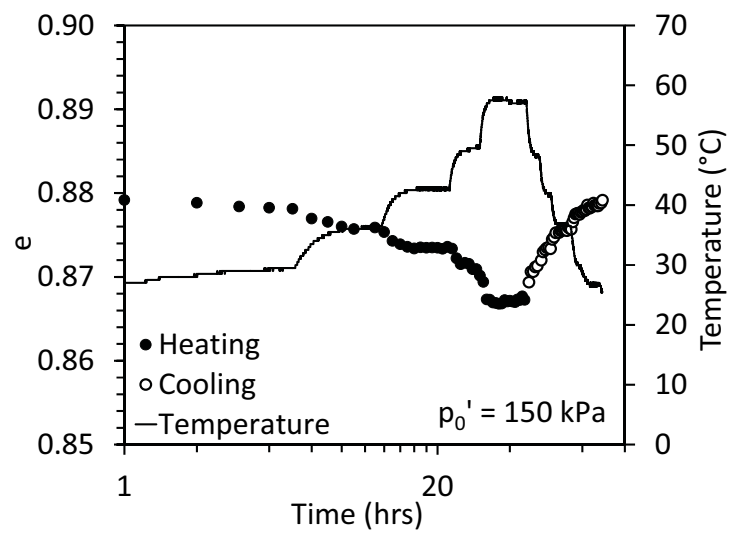

Fig. 4. Volume change during drained heating and cooling for the test at a mean effective stress of $150 \mathrm{kPa}$.

In all three tests, contraction was observed during drained heating. An interesting observation is that during cooling the thermal contraction was nearly recoverable. Although expansion during cooling has been observed in several experimental studies $[6,10,15]$, most constitutive models assume that soils will contract elastically during cooling. The formulation in the constitutive models is based on several studies that observed elastic contraction during cooling [1, 5, 13-14]. Care was taken in the current study to ensure that the volume changes during cooling were drained. 


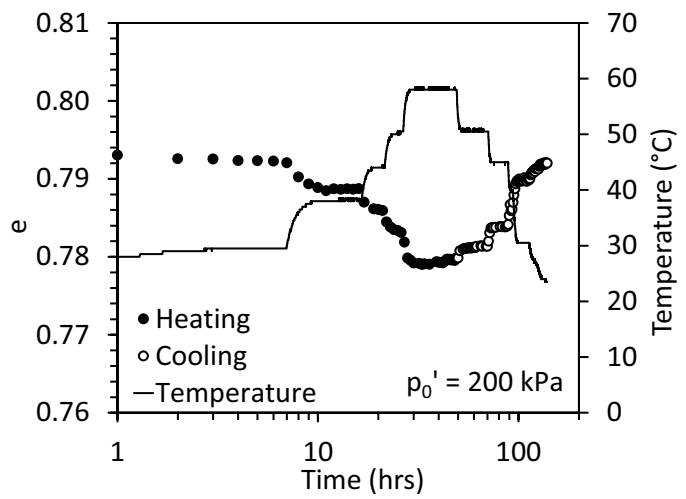

Fig. 5. Volume change during drained heating and cooling for the test at a mean effective stress of $200 \mathrm{kPa}$.

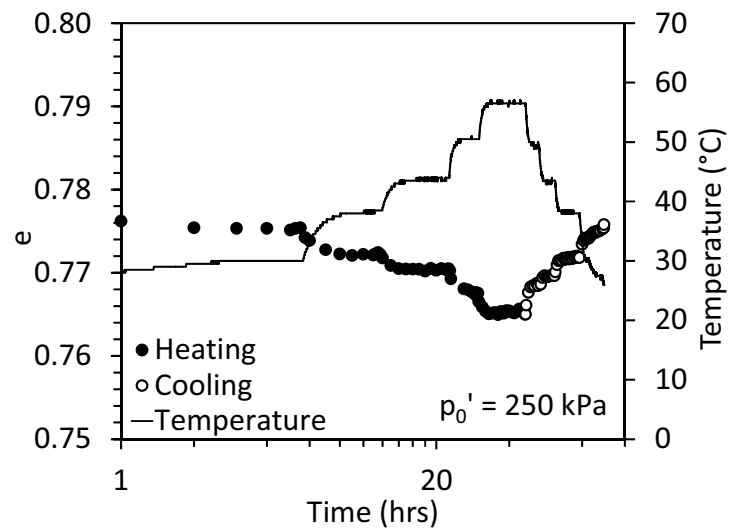

Fig. 6. Volume change during drained heating and cooling for the test at a mean effective stress of $250 \mathrm{kPa}$.

The change in thermal volumetric strain with temperature for the specimen at $200 \mathrm{kPa}$ initial mean effective stress is shown in Figure 7. Similar observations were made for the specimens at the other two initial stress levels. Although the contraction during heating agrees with the observations in literature from previous studies, the increase in void ratio during cooling contradicts with the general trend observed in the literature $[1,5,13-14,17]$. However, there exists several studies $[6,10,15]$ which observed thermal expansion during drained cooling.

The compression curve for the specimen initially subjected to a mean effective stress of $200 \mathrm{kPa}$ is shown in Figure 8 in the e vs $\ln \left(\mathrm{p}^{\prime}\right)$ plane. The specimen was first mechanically loaded to a mean effective stress of $200 \mathrm{kPa}$ where it is at a normally consolidated state. Then, the void ratio of the specimen can be seen to decrease during heating and increase again after cooling at the same mean effective stress level. Mechanical loading of the specimen after a heating cooling cycle showed overconsolidated behaviour, although the specimen was initially at a normally consolidated state. The slope of the compression curve, immediately after a heating cooling cycle is observed to be similar to that of the recompression index ( $\kappa)$ of the clay. The specimen regains a normally consolidated state at a higher mean effective stress, upon further loading. The slope in this section of the compression curve is similar to that of the compression index $(\lambda)$. This is in accordance with the thermal hardening phenomena described in literature where a soil specimen undergoes a hardening effect due to a change in temperature. The yield surface expands after a heating cooling cycle as illustrated in Figure 1 and as a result, a higher effective stress is required for the specimen to regain plastic deformation.

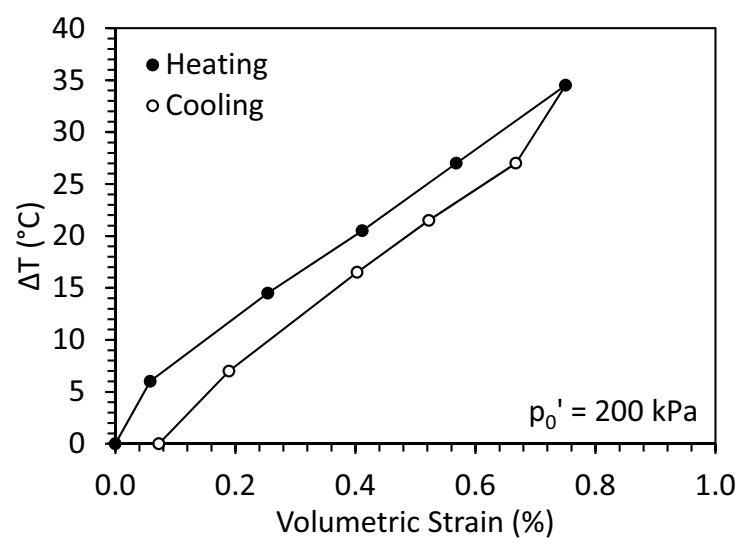

Fig. 7. Change in thermal volumetric strain with temperature.

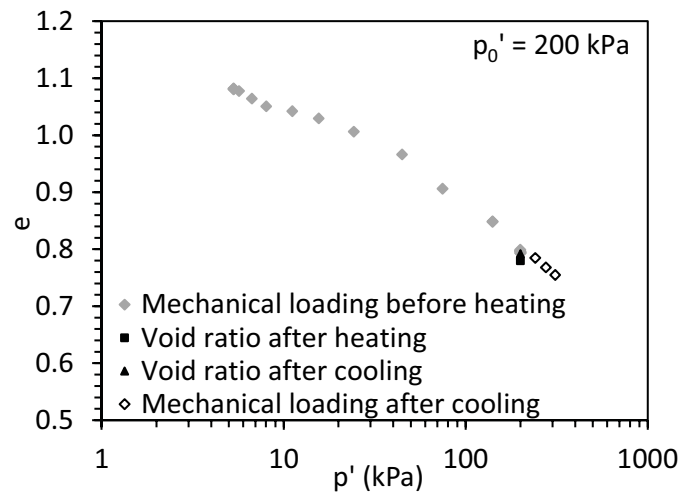

Fig. 8. Compression curve during thermo-mechanical loading for the normally consolidated clay consolidated to $200 \mathrm{kPa}$.

The thermal volumetric strains obtained at different initial mean effective stress levels were compared to investigate the effect of initial mean effective stress on the thermal volumetric strain. A comparison of the results obtained for the initial stress levels considered in this study is shown in Figure 9. The thermal volumetric strain observed as a result of drained heating up to $60{ }^{\circ} \mathrm{C}$ was $0.6 \%, 0.75 \%$ and $0.83 \%$ for specimens at initial mean effective stresses of 150,200 and $250 \mathrm{kPa}$ respectively. These values are in agreement with the typical strain values observed in the literature for normally consolidated clays. Thermal volumetric strains reported in the literature are in the range of $0.25-1 \%$ for illite [6], Boom clay [16-17], Pontida clay [15] and kaolin [18] heated up to $60{ }^{\circ} \mathrm{C}$ with the exception of Bangkok clay [1] where a $3.25 \%$ thermal volumetric strain was observed. An interesting observation in this study is that the thermal volumetric strain obtained during heating is observed to increase as the initial mean effective stress of the specimen increases. During cooling, volumetric expansion is observed at all stress 
levels. For the test at $150 \mathrm{kPa}$ initial mean effective stress, the volumetric strain obtained during heating was completely recovered during cooling, resulting in zero volume change. On the other hand, net contractive volumetric strains were observed for the tests at 200 and $250 \mathrm{kPa}$ initial mean effective stress. While the thermal response of the normally consolidated specimen at 150 $\mathrm{kPa}$ seems almost elastic, net plastic volumetric strain was observed for the specimens at 200 and $250 \mathrm{kPa}$ initial mean effective stresses after being subjected to a heating cooling cycle. It was interesting to notice that this net plastic volumetric contraction also showed an increasing trend with increasing initial mean effective stress. However, further investigation will be required to arrive at a definitive conclusion with respect to trends in thermal volumetric strain with initial mean effective stress.

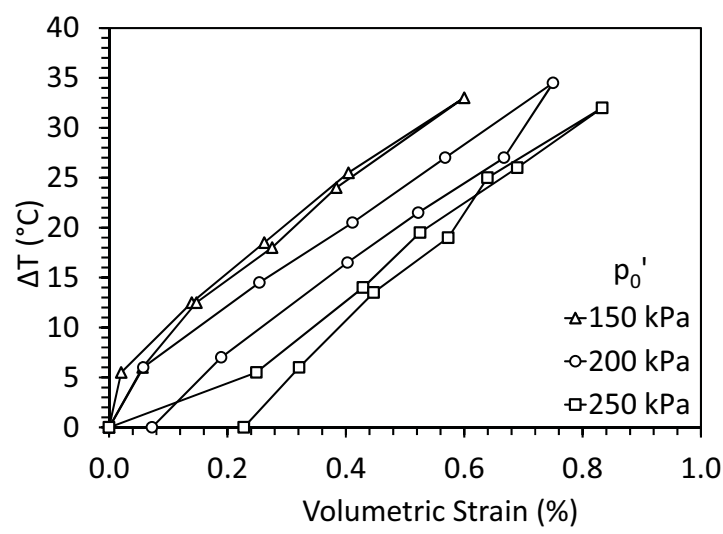

Fig. 9. Comparison of thermal volumetric strain of normally consolidated clays at different initial mean effective stresses.

The void ratio values prior to a heating cooling cycle, after heating, and after cooling for specimens at each initial mean effective stress level are summarized in Figure 10. Similar to the observations drawn from Figure 9, the contractive behaviour during drained heating and the expansive behaviour during drained cooling is observed from the results. However, these results are in contrast with the previous observations made by the authors [5], where a higher change in void ratio was observed at lower initial mean effective stresses. The authors attribute these inconsistencies to the differences in the experimental procedures followed. For a given mean effective stress, [5] obtained void ratio values from three separate tests conducted on specimens at room temperature, subjected to heating and a heating cooling cycle respectively. The void ratio for each test, was calculated at the end of the test, using specimen water content measurements.

Furthermore, the clay specimens in [5] were subjected to relatively fast rates of heating in contrast to the incremental step heating used in this experimental study. During the slurry preparation stage, the clay specimens were consolidated in a larger diameter cylinder where it was quartered at the end of the sedimentation process to obtain 4 separate triaxial test specimens. On the other hand, in the current test set-up each triaxial specimen is prepared individually starting from the sedimentation process and the volume change is measured during a single test throughout the heating cooling cycle. The differences in the experimental methods may have led to the inconsistencies in the results observed.

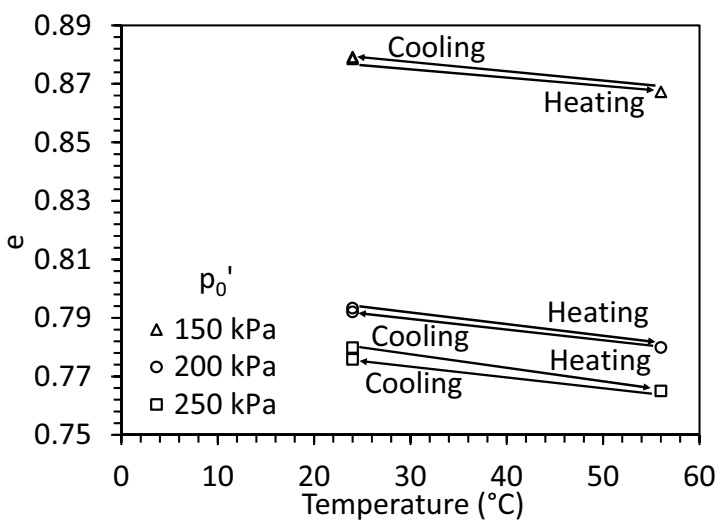

Fig. 10. Void ratio of kaolinite specimens at each stage of the heating cooling cycle.

The above results indicate that the thermal volumetric strain response of normally consolidated kaolinite specimens is dependent on the initial mean effective stress. Thermal volumetric strains obtained during heating seem to follow a trend where the volumetric strain increases with increasing mean effective stress. After a heating cooling cycle, the thermal behaviour observed in normally consolidated kaolinite specimens seem to transition from elastic deformation recoverable upon cooling to net plastic contraction as the initial mean effective stress increased. These observations contradict the available thermoelasto-plastic models where the magnitude of volumetric strain for normally consolidated soils after drained heating is predicted to be the same, irrespective of the initial mean effective stress.

On the other hand, some field tests [19], laboratory tests [20-21] and poromechanics theories [22] suggest that higher excess pore water pressures will be generated in soils with higher initial mean effective stresses during undrained heating. It can be reasoned that thermal excess pore water pressure generation will be linked with thermal volume change. However, the excess pore water pressure generation under partially drained or drained conditions can be small or negligible. Further studies on a broader range of soil types and stress levels will be required to better understand the trends of thermal volume change and improve the existing models incorporating the effect of initial stress on volumetric strain during a heating cooling cycle.

\section{Conclusion}

The results from an experimental study investigating the effect of initial mean effective stress on the thermal volume change of normally consolidated clay were presented in this study. Kaolinite specimens at three 
different initial mean effective stresses were subjected to an incremental heating cooling cycle. The experimental results show contractive volumetric strain during heating where the thermal volumetric strain increased with increasing initial mean effective stress. An expansive trend was observed during cooling and the net volume change after a heating cooling cycle changed from expansion to contraction as the initial mean effective stress increased.

Although not considered in existing constitutive models, the effect of initial mean effective stress on the thermal volume change of normally consolidated clays is a critical factor to be considered when configuring geothermal heat exchangers in a thermal soil improvement application. Further investigation on different soil types and stress states will assist in developing constitutive models used to assess the feasibility of geothermal heat exchangers for improving soft soil deposits.

Funding from NSF grant CMMI 1941571 is appreciated. The opinions are those of the authors alone.

\section{References}

1. H.M. Abuel-Naga, D.T. Bergado, S. Chaiprakaikeow. Innovative thermal technique for enhancing the performance of prefabricated vertical drain during the preloading process, Geotextiles and Geomembranes. 24, 359-370 (2006)

2. C. Pothiraksanon, D.T. Bergado, H.M. AbuelNaga. Full-scale embankment consolidation test using prefabricated vertical thermal drains, Soils and Foundations. 50, 599-608 (2010)

3. S.L. Houston, W.N. Houston, N.D. Williams. Thermo-mechanical behavior of seafloor sediments, J.Geotech.Eng. ASCE. 111, 1249-1263 (1985)

4. P. Kuntiwattanakul, I. Towhata, K. Ohishi, I. Seko. Temperature effects on undrained shear characteristics of clay, Soils and Foundations. 35, 147-162 (1995)

5. R. Samarakoon, I. Ghaaowd, J.S. McCartney. Impact of drained heating and cooling on undrained shear strength of normally consolidated clay, Proc. $2^{\text {nd }}$ Int. Symp. On Energy Geotech. Lausanne, Switzerland, Sep. 26-28. A. Ferrari, L. Laloui, eds., Vienna. 243-249 (2018)

6. R.L. Plum, M.I. Esrig. Some temperature effects on soil compressibility and pore water pressure, Highway Research Board, Washington DC, Report. 103, 231-242 (1969)

7. L. Laloui, C. Cekerevac. Thermo-plasticity of clays: An isotropic yield mechanism, Computers and Geotechnics. 30, 649-660 (2003)

8. H.M. Abuel-Naga, D.T. Bergado, A. Bouazza, G.V. Ramana. Volume change behaviour of saturated clays under drained heating conditions: experimental results and constitutive modelling, Can. Geotech. J. 44, 942-956 (2007)
9. Y.J. Cui, N. Sultan, P. Delage. A thermomechanical model for saturated clays, Can. Geotech. J. 37, 607$620(2000)$

10. N. Tanaka, J. Graham, T. Crilly. Stress-strain behaviour of reconstituted illitic clay at different tempertaures, Eng. Geology. 47, 339-350 (1997)

11. N.A. Alsherif, J.S. McCartney. Nonisothermal behavior of compacted silt at low degrees of saturation, Géotechnique. 65, 703-716 (2015)

12. A. Uchaipichat, N. Khalili, S. Zargarbashi. A temperature controlled triaxial apparatus for testing unsaturated soils, Geotech. Testing J. 34, 1-9 (2011)

13. G. Baldi, T. Hueckel, A. Peano, R. Pellegrini. Developments in modelling of thermo-hydrogeomechanical behaviour of Boom clay and claybased buffer materials, Commission of European Communities, Nuclear Science and Technology, Report EUR 13365. (1991)

14. N. Sultan, P. Delage, Y.J. Cui. Temperature effects on the volume change behavior of boom clay, Eng. Geology. 64, 135-145 (2002)

15. T. Hueckel G. Baldi. Thermoplasticity of saturated clays: Experimental constitutive study, J. Geotech. Eng. 116, 1778-1796 (1990)

16. G. Baldi, T. Hueckel R. Pellegrini. Thermal volume changes of the mineral-water system in low-porosity clay soils, Can. Geotech. J. 25, 807-825 (1988)

17. P. Delage, Y.J. Cui, N. Sultan. On the thermal behaviour of Boom clay, Proc. Eurosafe Conf. Berlin, Germany. 1-8 (2004)

18. C. Cekerevac, L. Laloui. Experimental study of thermal effects on the mechanical behaviour of a clay, Int. J. Numer. Anal. Meth. Geomech. 28, 209228 (2004)

19. L. Bergenstahl, A. Gabrielsson, M. Mulabdic. Changes in soft clay caused by increases in temperature, Proc. $13^{\text {th }}$ Int. Conf. on Soil Mech. and Foundation Eng. New Delhi, India. Jan 5-10. 16371641 (1994)

20. A. Uchaipichat, N. Khalili. Experimental investigation of thermo-hydro-mechanical behaviour of an unsaturated silt, Géotechnique. 59, 339-353 (2009)

21. I. Ghaaowd, A. Takai, T. Katsumi, J.S. McCartney. Pore water pressure prediction for undrained heating of soils, Env. Geotech. 4, 70-78 (2017)

22. R.G. Campanella, J.K. Mitchell. Influence of temperature variations on soil behavior, J. Soil Mech. and Foundation Div. ASCE. 94, 709-734 (1968) 